\title{
Indonesian Students' Negotiation of Identities through Language Use in England
}

\author{
Komilie Situmorang \\ Faculty of Nursing, Universitas Pelita Harapan, Tangerang, Indonesia
}

\begin{abstract}
Study abroad (SA) is a daunting process in which students who encounter cross-border face a whole new world. They go through positioning and being positioned by others. There is an on-going salient power asymmetry in their language use, which affects their desire to speak up and participate in the new community. This study aimed to scrutinize the ways Indonesian students negotiated their identities through their language use. Using open-ended questionnaires (OEQ)and semi-structured interviews, this study focused on 7 participants who were in the midst of the master's degree program in England. The results indicated that the participants experienced the identities negotiation multifacetedly. Participants who exercised their agency and invested in their language use challenged the positioning attached to them. As a result, they constructed new identities and gained central participation in the local community. Meanwhile, participants who could not resist the power asymmetry withdrew and formed a more solid community with other international students. Lastly, some participants were also found to maintain their emotional security by not making any contact through their language use. Participants who resisted any contacts but with fellow home students interestingly developed an increased nationalism. Therefore, this article calls for the teachers' attention and how to devise the English Language Teaching classroom better and program providers' of how to provide the support for the SA students best.
\end{abstract}

\author{
ARTICLE HISTORY \\ Received 15 April 2020 \\ Accepted 17 June 2020 \\ Published 31 December 2020
}

\section{KEYWORDS:}

Agency, identity negotiation, investment, language use, study abroad

\section{Introduction}

Study abroad (SA) is always dreamlike until one gets into it. Not a few assume that crossing the border is the best way to learn English (Kinginger, 2013). This assumption is made logical by the concept that when immersed in the language, one will quickly grasp the feel and the maximum exposure to the language. However, the process is not that simple. Savicki and Cooley (2011) state that every linguistic and cultural context encounter requires adjustment and adaptation. When looking at it closely, the students' participation and non-participation prove to be daunting. They have to position themselves in a completely new situation and are subject to be positioned. To describe this process, Kinginger (2013) summarizes that "some students thrive while other flounder" (p. 341).

While Campbell (2015) believed that SA could be the best medium for the students to gain language proficiency through frequent interaction, it is a battlefield in which there is an on-going invisible power. There is a large gap between the native speaker and the non-native speakers. Learners who come to a new community is not solely accepted and made as a central participant. They need to display the required

CONTACT Komilie Situmorang 区 komilie.situmorang@uph.edu 圆 Faculty of Nursing, Universitas Pelita Harapan, Tangerang, 
capital like accent, fluency, and cultural awareness to be accepted in the community. Moreover, learners need to have a strong commitment to resist and position themselves for their favors. In other words, they have to be able to fit or reorganizes themselves when rejected. Many experiences despair that they withdraw themselves, putting off their desires to join the community, although some succeed.

Various studies have looked into the international students' identities negotiation in different countries during SA. Identities that are studied include nationality, gender, age, ethnicity, and foreigner identities ((Kinginger, 2008; Polanyi, 1995; Pellegrino-Aveni, 2005; Tan and Kinginger, 2013; Lino, 2006). Within this research, investment and agency have gained popularity as the drive to negotiate the identity (Darvin, 2019; Norton 2017). As many studies have been looked into the different international students' identities in SA, some Indonesian research has also shifted their focus to the Indonesian identities in SA. Sabaruddin $(2019$, p. 37), an Indonesian student learning in Australia, reflected that "students can be successful if they are willing to socialize and intensely be involved in the culture of the country they study." Mardiningrum's (2017) study on five EFL teachers in the US indicated that the participants perceived that they lacked English proficiency and struggled to keep up with the native speakers. There are only limited studies done in the context of Indonesian in SA, yet they both confirmed the real struggle in SA.

There is an urgent need for more empirical studies to uncover students' struggles during SA and how they negotiate their multiple identities in different cultures. As no studies have been done in the United Kingdom (UK) context, this study offers a novel perspective. It enriches the literature of Indonesian students' negotiation of identities in study abroad. Therefore, this study provides real pictures from the fields, which are the students' voices. The findings can offer more precise insight into the teachers' attention in devising the English language teaching classroom and program providers to think of ways best to support SA students.

Due to the arguments mentioned above, this present studied was set to uncover: 1) In what ways do the Indonesian students negotiate their identities during the SA?

\section{Literature Review}

\section{Identity Negotiation}

When learners cross the border, they make sense of who they are, what they want to be, and their relationship to their new context. Norton (2000, p. 5) defines this making sense process as identity negotiation in which she explains it as "how a person understands his or her relationship to the world, how that relationship is constructed across time and space, and how the person understands possibilities for the future." This definition explains that identity is fluid, flux, multiple, and continually constructed across time and space.

In negotiating the new identities, the learners will add and drop the community and socialize to gain validation and central participation (Lave and Wenger, 1991). They strive to be accepted in the community by their language use. However, language use and participation are the real battlefields where power asymmetry is structured internally. To be considered the central participants, the learners need to have the 'right capital', including the right accent and the right attitude qualities (Bourdieau, 1991). Therefore, the process of identities negotiation is long and exhaustive.

Previous studies have provided empirical evidence that learners may accept or reject the community they aim for when trying to gain participation. Rejection will mostly lead to two results. First, the learners will find another community that will support him to construct his desired identity formation (Norton and Toohey, 2011), switch again and again, and find available support (Heller, 1992), and second, the learners resist negotiating their identity as a consequence from suffering the 'symbolic domination' - the condition where they are seen as incapable of participating. Another possibility can be that they position themselves as illegitimate as they believe they are not the rightful speakers (Pavlenko and Blackledge, 2004). Therefore, learners in SA are highly suggested to actively position and reposition themselves for their favors. They need to keep making sense and participate through the language practice and the cultural encounters because identities negotiation is "not simply in as discursively constructed categories of self but as lived experiences of participation in specific communities, where meanings of particular positions, narrative and categories must be worked out in practice" (Pavlenko, 2011, pp. 319).

Furthermore, it has also been suggested that negotiating identities is the interplay between how others position and reposition the learner (interactive positioning) and how learners position themselves in the context (reflective positioning) (Pavlenko and Blackledge, 2014). Interactive positioning challenges 
the learners directly when having interaction. When they talk with native speakers and cannot grasp or respond, they may be excluded from the conversation. Equally, in the same situation, their reflective positioning is also challenged in which they will voluntarily position themselves as incapable speakers. The backlash, however, is less intense if the conversation is made through media. Learners who receive an email or message may have a longer time to think before replying, leading them to a more positive positioning.

Support available from the host community has been working in two ways. The finding shows that support availability gives learners room to speak (Pellegrino, 2005). The students feel that they are not struggling alone because they feel supported. Meanwhile, another finding has shown that learners despise the support availability because it makes them look incapable and humiliated thus decide not to use the support (Duff, 2002). Therefore, whether or not support should be available seeks an answer in this study.

\section{Investment and Agency in Identity Negotiation}

The notion of motivation in second language acquisition theory is claimed not enough to explain why a motivated student gives up speaking when faced with the desired context (Darvin and Norton, 2015; Norton 2000). More than motivation itself, the student needs a commitment to the learning that "accentuated the role of human agency and engaging with task at hand, accumulating economic and symbolic capital, in having stakes in the endeavor and persevering that endeavor" (Kramsch, 2013, p.195). Therefore, rather than solely relying on the traditional conceptions of good and bad, motivated and unmotivated, introvert and introvert learners, we need to dive deeper into the learners' learning commitment of what we call the investment.

Learners invest in their language learning because they know that they will achieve something good in exchange for learning. Investment indicates the willingness to engage in language learning regardless of the marginalization experienced due to the power asymmetry. Being invested, the learners will supposedly position and reposition themselves through situations and find a place where they can claim their voice. Investment is used to "capture the relationship of the language learner with the changing social world. It conceives the language learner as having a complex social identity and multiple desires. The notion presupposes that when language learners speak, they are not only exchanging information with target language speakers, but they are constantly organizing and reorganizing a sense of who they are and how they relate to the social world" (Norton Pierce, 1995: p.17-18). Therefore, investment is an inseparable part of the negotiation of identities as it is the bridge between the social and the historical relationship of the learners to the language.

Investment is found to lead to much higher retention in the classroom. Ryan (2012) in Norton (2017) shows that only 9/25 students attend the class before explaining the concept of investment. However, after the explanation, 25/29 students are attending the class. Besides, learners who invest in their language learning will voluntarily abandon their comfort zone and find the target language community to acquire the proper language learning (Wallace, 2003). The previous study of Jackson (2008) indicates that two of her participants consider that they should not wait to be accepted and are responsible for building the relationship. Therefore, they invest in their time and energy.

Language choices, control over investment, negotiation, participation, and non-participation are maneuvered by human agency. Human agency highlights the struggle in the situation where a learner can say 'no' to marginalization. Galluci (2011) shows that a student named Lucy validates her status as a powerful English speaker when she feels that she cannot challenge her flatmates to keep speaking Italian to her but a mixture of Sardinian and Spanish. This evidence indicates that through human agency, learners can challenge the positioning imposed on them by negotiation or resistance. To resist, learners may set up a counter-discourse that positions them as powerful persons rather than a marginalized subject position (Norton, 2000). So, human agency is a "socially mediated capacity to act" which works together with investment to decide whether to negotiate or resist. 


\section{Methodology}

This study aimed to explore and understand the natural meaning in a social problem and how they are coped (Cresswell, 2013). Therefore, the research used qualitative research as it aimed to get "the bottom of what is going on in all aspects of social behavior" (Holliday, 2015, p. 50), and its design took the form of a case study. Yin (2014) mentions that a case study can, at the same time, help to examine the real-life and define the complexities which cannot be explained by survey research. Therefore, the case study design was chosen because of its feasibility in eliciting explicit and implicit data from the dynamic participants. Purposive and homogenous sampling criteria were utilized, and 7 participants were recruited. The participants were coded as Aif, Lanno, Sota, Putri, Wenger, Meza, Aldi, postgraduate students in a University in England. Data collection was done through open-ended questionnaires (OEQ) and semistructured interviews. OEQ acted as the familiarisation to the topic, and the semi-structured interview was used to explore and confirm the data from the OEQ (Vasilopoulos, 2015). The data collection underwent the process of collection, transcription, and member checking. The data analysis between the OEQ and the semi-structured data was not done separately but in integration. The data were analyzed using qualitative content analysis designed to "provide knowledge and understanding of the phenomenon under study" (Downe-Wamboldt, 1992: pp.314). The categories were gained after rereading the data and making sense of the connections made in the data. This is in line with Cohen et al. (2007), who suggests establishing the codes that flow from the data to gain a rich data pool instead of making pre-ordinate categories. The data analysis is shown through decontextualization, recontextualization, categorization, and compilation (Bengtsson, 2016). After rereading the data and making sense of the emerged codes and the categories, the analysis results in three big themes. Each theme represented the participants' different ways of negotiating identities.

\section{Results and Discussions}

\section{Constructing new identities - I am part of the community Lanno and Wenger}

Two participants demonstrate their desire and commitment to construct their new identities through their voluntary moves to approach the locals. This willingness is then interpreted as an investment because they understand that they will get what they expect in return. Knowing that exposure to different cultures will improve his personality and expand his career opportunities in the future, Wenger invests in his language participation.

I can come to a new culture that will improve my thinking, habits, and perspectives, which will be beneficial and enriching. By living independently and getting in touch with the new culture, I will be able to do networking and get out of my comfort zone. I am glad that I am in many ways helping myself to improve. (Wenger)

Enacting SA, these two participants find that interacting with locals is not as easy as they once imagined. The locals do not necessarily open up and welcome their presence (Pellegrino, 2005). They are put in a situation where they feel powerless when using the language. They feel that they are invisible and thus experience the situation where they feel marginalized.

It is not easy to talk to people. Why? Because they are BRITISH, it is their language. They would not want to waste their time just talk to us. They look LAZY and unwilling to talk to us; some are nice, though. I am not sure whether they originally are unsociable. I think they may be introverted. Yes, probably they are introverts who prefer to talk only to people of their kind. (Lanno)

Through Lanno's excerpt, when emphasizing BRITISH, it can be seen that Lanno is aware of the 'language ownership' notion. He is aware of the asymmetrical position between the legitimacy owned by the locals against them. Lanno is positioned as the 'foreigner' who look for chances to talk in English. Therefore, they would not talk to him because they see him as someone with limited command. They exclude him from the talk and not giving him room to speak (Pavlenko and Blackledge, 2004). The use of human agency is seen to be exercised during this situation. Lanno, however, challenges the position given to him by repositioning the way he sees the locals. Instead of saying that his friends are excluding him, he sees them as introverts. He does not allow the prejudicial attitudes to limit him from approaching the locals. He 
denies the on-going power difference and assumes that being introverted is why they will not talk to Him. As a result, he decides to keep talking to them.

Wenger also experiences a very similar situation. He shares the unbalance linguistic power situation in his classroom. He asserts how real the struggle is. There is a salient difference found in using the language, and he calls it a barrier. For example, when he tries to speak, he cannot get a slot because his classmate does not let him. He even feels intimidated to speak. He indeed makes contact with the locals when sitting in the class but only to a certain extent.

I don't speak the language fluently, which is probably why they have difficulty communicating with me. I mean, it so different between the EAST and the WEST in many terms. I don't speak to my classmates. They DOMINATE, and in some way, I feel INTIMIDATED. I usually talk to international students. We encourage and listen to each other. (Wenger)

Wenger finds himself silenced in the class as he positions himself to be in the powerless position. Bluntly he explains how he feels dominated to be around his local classmates. He, too, using his human agency, resists the position opposed to him by not speaking to his classmates often. Simultaneously, he still uses the language but in a less harmful way with his fellow international students, where he acquires support.

Analyzing the two situations faced by Lanno and Wenger, it can be seen that both of them experience the so-called invisible marginalization. They are both positioned unequally because they could not display the required language to join the locals (Bourdieu, 1991). Wenger contrasts the difference between using the language to the locals and the international students. On one side, he positions himself as a marginal speaker as he emphasizes that his local friends 'have difficulty when communicating' with him. On the other side, he feels supported when talking to his international friends because they can understand each other. In this case, both Lanno and Wenger experience symbolic domination, which forces them to validate the Languages' ownership to validate the Languages' ownership to validate language's ownership. British owns the language. The analysis uncovers that English used, among Lanno, Wenger and their friends is not as solely a medium of communication but as a vehicle of power that medium of communication but as a vehicle of power that validates the inequality between the owner and the sole user. Using their human agency, both Lanno and Wenger reorganize the positioning opposed to them in different ways. Instead of withdrawing themselves, they gradually show salient effort as they are aware of the benefit if they are continuing to gain participation in the local community. They seek new ways into the interactions (Heller, 1992) and resist the label of incompetency.

Through several efforts, Lanno exercises his agency. Although being put unequal due to his limited command, he sticks to his local friends. He starts as a peripheral participant by joining friends in pub quizzes and investing his time in meet-up drinks and gatherings. He indeed pays the price to move from a peripheral into central participation. Investing time and paying prices do benefit Lanno. His determination to fight back for the positioning imposed on Him results in him considered central to the pub quizzes and drinks on the weekend.

I try to avoid Indonesians, and here, my campus is in a remote area. My classmates always hang out in the pub or somewhere in the city. I have to give EXTRA EFFORT because I have to walk a mile from the dorm to the bus stop if I want to join them. The bus frequently comes late, it could be 10 minutes, and at worst it could be 1 hour. Besides, I must work twice harder in my study if I want to join them because I need to digest the language slower than them, so I am pressing myself to follow their pace. As a result, when my British and American friends invited me to the weekend for a drink, I have been relaxed, and I say, Yes, I am in. (Lanno)

Wenger also displays a similar struggle. Having been turned down by his local classmates, he seeks other communities that will support him in developing his local community participation (Norton and Toohey, 2011). He decides to volunteer in a charity shop, which serves as his incubation tube of becoming a centric participant. In this shop, he meets the elderly, who are surprisingly very friendly and welcome. He gains confidence because the elderly see him as a fellow worker and listens to him. As a result, he subscribes to the charity shop cultures and repositions himself as confident speakers. He is given access to speak about his interests and various topics. His investment is paid off with him forms bonding with the charity shop's community. He remains as peripheral in his classroom but central to the charity shop. 
I volunteer at a charity shop to gain exposure to the locals, and I am glad that I do. I meet retired elderly who are very nice and kind. We talk about a lot of things, like issues happening in England, sports and different views. I like how they APPRECIATE me the way I am and ACCEPT me. (Wenger)

Both Lanno and Wenger experience the powerless situation through their language uses. On one side, Lanno repositions the way he sees the marginalization by taking the benefit from the way he looks at them as introverted. On the other side, Wenger resists the marginalization by abandoning the community to find another community that will better support him. He displays a similar finding to Pellegrino's (2005) study that locals do not always welcome international students friendly. Therefore, support from the host is inevitably vital as they help the students boost their confidence to use the language.

Human agency also drives Lanno and Wenger to reposition themselves from unfavorable situations to their imagined favorable situations. The price they paid is manifested in their investment in joining the community. Although they are marginalized at first, Lanno repositions himself and resists the positioning by sticking to the locals until they validate him as a community member. Meanwhile, Wenger resists the powerless situation by finding the community that will support him. He eventually finds the charity shops community by perpetually negotiating his identities across the different communities.

Through Lanno and Wenger's experience, it is evident that agency and investment play essential roles in negotiating the identities. The agency drives learners to resist or to bend during the marginalization while investment keeps them going during the difficult times. As a result, they gain central participation in the community they aim. In the case of Lanno and Wenger, they expand the learning outside the class. They exercise their agency while investing in their language learning outside the classroom, such as going to the pub meet-ups and volunteering in charity shops. As a result, they subscribe to a more natural and flexibly fun conversation. Galluci (2011) argues that significant language learning and identities negotiation more likely to take place for Lanno and Wenger.

\section{Growing with the Imposed Positioning - I will soon be part of the community Sota}

The second finding shows that identity can be negotiated through marginalization by seeing it as unproblematic. Sota experiences a powerless situation when talking to his local classmates. He is rejected from the engagement and not included in the classmates' talk.

I have many international friends, but I don't have locals, I mean, I have some classmates, but we are not very close to each other. They HAVE JOBS, so it's difficult to get together. It is hard to have time together.

Arguably, it is not merely because they are too busy or because they have jobs. There is a salient emergence of the marginalization simply because he cannot demonstrate the required linguistic capital needed for the talk to start with (Bourdieu, 1991). Being busy is merely a way to say that Sota is 'inguistically incapable.' This argument is generated after the story about the classroom situation is explained by Sota. His professor has made clear the on-going power difference between the local and the international students. The professor has been speaking very slowly from the first time, so the international will catch what he is saying and advising the local students to do the same. Furthermore, the professor has set the rules that international students should get the chance to speak first before any of the local students. The following excerpt strongly supports the claim that instead of being busy, the local students refuse to talk to him and position him as solely someone incapable.

My professor is so kind and understanding. He knows our situation. They speak very slowly to make sure we understand and make the local students' policy to do the same to understand the discussion. What's more, we are given the privilege to speak first in any discussion. As soon as we, the international students, have no question, it will be given to the local students. It's exciting, and I like it.

What can be inferred from the excerpt is that Sota must have first positioned himself as someone incapable of English before coming to the class. He has feared that he will not understand what the professors and his local friends say, which is why he feels supported when offered the privilege in the classroom. To put it in other words, he does not resist the positioning impose on him but lives with it. He views his powerless 
states as a way to get help and thus appreciates the help given. This support helps his language learning and provides him room to speak up in the classroom. However, Sota's experience contrasts with Duff's (2002) participants, who use their agency to ignore and remain silent in the class to avoid humiliation from their classmates.

It is remarkable how Sota uses his human agency to self-position himself as an incapable speaker and remains engaged in the class positions him as an outsider. He also invests in the interaction by capturing the privilege to speak because he sees that he will be improving his language learning and academic achievement as benefits. Although his local friends now refuse to talk to him after class, he experiences favorable identity negotiation, which puts him in a positive situation. Evidently, in addition to the agency's use, Sota's positive self-positioning amidst the marginalization of his language use owes to the support availability. This finding highlights the importance of support available to positively support students' self-strength and confidence and affect their identities formation. Thus, although Sota is yet a peripheral participant, using the support and his agency, he can follow the learning trajectories in the class and reformulate his identity.

\section{Identities formation - I am a non-native speaker \\ Putri}

Putri expresses the salient powerless state to be among her classmates. She bluntly claims that she suffers from being around her classmates and thus position herself as a marginal speaker. Putri sees a significant inequality of power between the British and her. She feels deserted and homesick.

When I first came, I missed home a lot. It is entirely different from what I have imagined before. It so hard to adapt to other languages. There is this 'LANGUAGE BARRIER' between us. It is entirely hard to INTERACT and FOLLOW them in conversation because they usually talk just to each of them, the Brits.

From the excerpt, it can be seen that Putri had imagined living in harmony with her language use. However, after trying to interact with locals, she realizes that it is not as easy as she has dreamed. She cannot follow her friends' speech and is positioned as 'incapable.' Being in the situation where she is set as the outsider, Putri is forced to admit her British friends (Bourdieu, 1991). Moreover, the classroom language is not solely a tool of communication but as a tool of power to indicate ownership. She is led to realize that she does not demonstrate the required capital, so she is not right to be in the conversation. Her notion of 'language barrier' helps understand the demarcation line between her and the local students (Pavlenko and Blackledge, 2004).

Suffering from the marginalization, Putri uses her agency to resist new ways to engage with the local students. She withdraws herself from the powerless situation. Instead, she seeks a community where she feels safe and owns equal power to speak - a place where English is used to communicate and support each other. She feels linguistically comfortable with her international fellow students, who are also nonnative speakers. With this community, she develops her confidence in using the language. Her English improves, and she experiences improvement. Indeed, dropping her desire to be in the local community does her less damage.

I am close with international students; there are like ten international students coming from Mexico, Japan, and Singapore. They become my close friends. My Singaporean classmate, who is also my flatmate, becomes my very important support system. She helps me proofreading my paper. Since we come from, she is so kind, and I mean Indonesia and Singapore are close enough, we feel like neighbors, that kind of sistership, keeping each other.

Choosing to make no more meaningful contact with the local students, Putri finds a community where she negotiates her new identity as a non-native speaker. She actively uses the language and ends up with much better English proficiency. She and her other international students use non-imposing English, and they grow together without power marginalization as non-native speakers. 


\section{Resisting Identity Formation \\ Aif, Aldi, and Meza}

Some participants use their agencies to block contact with the local students and international students because of the marginalization, resulting in bad experiences. Aif suffers the salient power inequality, which positions him as an incapable speaker.

BRITISH students are very different from us. Some of them are polite, but some are not. Some are nice when asked, but some LOOK US DOWN. We are being careful talking to them because they give an unfriendly impression every time we talk. (Aif)

Commenting on the difference between the British and him, Aif implies the validation that his British friends are the rightful speaker. He also bluntly expresses how powerless he is against his friends when he opens his mouth. This condition forces him to stay silent not to be humiliated or looked down on when using the language. His interest in participating in the class is greatly diminished, and he opts for silence. He remains silent during the class and emails the professor when having a question to avoid being seen as stupid. This finding aligns with Duff (2002) whose participants choose to stay silent because they are afraid to be laughed at by their friends. Though he was first thinking of having the British accent, now he protects himself and is no longer motivated. He cuts the idea of developing bonds with the local students.

Further, Aif does not necessarily develop a bond with international students because of his flatmates' bad experiences. His flatmates happen to be very noisy and eat his food frequently without asking first. His bad experiences provoke his resistance toward creating bonding with them. He is now prejudiced against both locals and international students. As a result, he speaks Bahasa Indonesia as a counterdiscourse, the language in which he is powerful and legitimate. He speaks Bahasa Indonesia all time and meets up with Indonesian during his free time.

Meanwhile, Meza and Aldi see their study abroad as a transit terminal which they only need to pass for their goal. They both avoid the contacts because they have first positioned themselves as incapable and foresee that it will be difficult to talk to locals. Therefore, they play safely in their comfort zone and maintain their emotional security.

I don't go out very often, so I don't talk to people very often. Only if I must. My brain is an Indonesian brain, so when I want to speak English, I need to think for a while and translate it in my mind. (Aldi)

I speak Bahasa Indonesia, not English because I spend most of my time with Indonesian friends. (Meza)

Aldi and Meza limit themselves from interacting with locals consciously. They both do not experience identity formation because they do not make any meaningful interaction with either local or international students. It is arguable because they do not value the interaction as something that will benefit them. Instead, they use their agency to go and meet their Indonesian friends whenever they have time. The interesting thing to point out is that they have increased awareness of being Indonesian after being in England. Meza feels extreme nationalism after meeting with the diasporas who tell her stories about their desire to go home from the land of the minority. She subscribes to their story and thus creates a conception that she will need to home afterward. Similarly, at the same time, Aldi experiences the sense of being an ambassador who bears the image of his country.

I am an Indonesian ambassador, a representation of my country. I need to behave, so they will not have a bad impression of Indonesia. (Aldi)

Aldi holds his identity as an Indonesian speaker though he is on a SA program. He wants to make a favorable impression about Indonesia by holding upright Indonesia value during his time in the UK. This finding is in line with Dolby's (2007) and Kinginger's (2008) studies in which American students try to behave during their SA program to erase the prejudicial concept about America.

Looking at Meza's and Aldi's excerpts, it can be concluded that they do not necessarily experience direct marginalization as the reason why they resist the interaction. Resisting interaction can be due to their own-self positioning as Indonesian and their less desire to interact with the locals. They feel powerful and linguistically at ease when speaking Bahasa Indonesia and meeting with Indonesian. As a result, they make no identity formation as they only make contact when necessary. Their language learning trajectories 
also do not seem to experience improvement because they speak Bahasa Indonesia all the time.

\section{Conclusion}

The ways Indonesian students negotiate their identities multifacetedly according to their agency and investment to endure with the situations. Lanno and Wenger reorganize their self-positioning and the positionings imposed on them. Sota grows with support, given though the marginalization seems to be very salient. Putri establishes her new identity as a non-native speaker, thus use the language to communicate and support each other. In contrast, Aif uses his agency to resist contacting local and international students speaking Bahasa Indonesia, where he feels powerful. Meza and Aldi use their agency to remain in the safe zone without attempting to make contact.

Another thing to conclude is that motivation itself is not enough to describe why learners want to study or quit. The struggles experienced by the participants of this study show that learners need to invest - commitment and have a clear goal of why they need to learn something and thus use their agency to help them maneuver their choices.

This research calls to the English teachers' and program providers' attention as an implication. Teachers in the classroom can now swift their views of being in the middle of the native speakers may create the best learning conception is not entirely true. There is an invisible power inequality that challenges the students and shuts down their motivation. Therefore, teaching them the concept of an investment of why they learn English will benefit them more. For program providers whose original purpose is to have the students back with global identities and competencies, they need to think of a way to support them. This could be done by making the pre-departure and teaching the pedagogical initiatives based on pre-existing research.

\section{Acknowledgments}

The author would like to thank Universitas Pelita Harapan for the material and moral support is given while writing this paper.

\section{References}

Bengtsson, M. (2016). How to plan and perform a qualitative study using content analysis. Nursing plus open. 2 8-16 https://doi.org/10.1016/j.npls.2016.01.001

Bourdieu, P. (1991). Language and symbolic power. Cambridge: Polity Press.

Cohen, L., Manion, L., \& Morrison, K. (2007). Research Methods in Education. London: Routledge/ Falmer. https://doi.org/10.4324/9780203029053

Creswell, J. W. (2013). Research design: qualitative, quantitative, and mixed methods approaches. Los Angeles, Sage Publication.

Darvin, R. (2019). L2 Motivation and Investment. in Lamb, M. The Palgrave Handbook of Motivation for Language Learning. https://doi.org/10.1007/978-3-030-28380-3_12

Darvin, R., \& Norton, B. (2015). Identity and a Model of Investment in Applied Linguistics. Annual Review Of Applied Linguistics, https://doi.org/10.1017/S0267190514000191

Dolby, N. (2007). Reflections on nation: American undergraduates and education abroad. Journal of Studies in International Education, 11(2), 141-156. https://doi.org/10.1177/1028315306291944

Downe-Wamboldt, B. (1992). Content analysis: Method, applications, and issues. Health Care for Women International, 13, 313-321. https://doi.org/10.1080/07399339209516006

Duff, P. (2002). The discursive co-construction of knowledge, identity, and difference: An ethnography of communication in the high school mainstream. Applied Linguistics 23, 289-322. https://doi.org/10.1093/applin/23.3.289

Gallucci, S. (2011). Language learning, identities and emotions during the year abroad. University of Birmingham.

Heller, M. (1992). The Politics of Code Switching and Language Choice. Journal of Multilingual and Multicultural Development, 12 (1\&2), 123-142https://doi.org/10.1080/01434632.1992.9994487 
Holliday, A. R. (2015a). Multiple discourses in developing intercultural awareness: everyday small threads culture formation on the run. Paper presented at the British Association of Applied Linguistics Annual Conference, Aston University

Jackson, J. (2008). Language, identity and study abroad. London: Equinox.

Lave, J. \& Wenger, E. (1991). Situated learning. Legitimate peripheral participation. Cambridge: Cambridge University Press. https://doi.org/10.1017/CBO9780511815355

Mardingingrum, A. (2017). EFL Teachers' Linguistics Self-Concept in a Study Abroad (SA) program. Journal of Foreign Language Teaching and Training 2(2) 27-37

Norton Pierce, B. (1995). "Social identity, investment and language learning". TESOL Quarterly. Vol. 29, 9-31. https://doi.org/10.2307/3587803

Norton Pierce, B. (2000). Identity and Language Learning. Gender, Ethnicity and Educational Change. Harlow: Pearson Ed. Ltd.

Norton, B., \& Toohey, K. (2011). Identity, language learning, and social change. Language Teaching, 44(4), 412-446. https://doi.org/10.1017/S0261444811000309

Norton, B., \& De Costa, P. (2017). Research tasks on identity in language learning and teaching. Language Teaching, 51(1), 90-112. https://doi.org/10.1017/S0261444817000325

Kramsch, C. (2013). Cultura no ensino de lingua estrangeira* / Culture in Foreign Language Teaching. Bakhtiniana, 12(3), 134-152. https://doi.org/10.1590/2176-457333606

Kinginger, C. (2008). Language learning in study abroad: Case studies of Americans in France. Modern Language Journal Monograph, 1. Oxford: Blackwell. https://doi.org/10.1111/j.15404781.2008.00821.x

Kinginger, C. (2013). Identity and Language Learning in Study Abroad. Foreign Language Annals, 46(3), pp.339-358. https://doi.org/10.1111/flan.12037

Pavlenko, A. \& Blackledge, A. (eds.) (2004). Negotiation of identities in multilingual contexts. Clevedon: Multilingual Matters. https://doi.org/10.21832/9781853596483

Pavlenko, A. (2011). Thinking and Speaking in Two Languages. Bristol: Multilingual Matters. https://doi.org/10.21832/9781847693389

Pellegrino Aveni, V. (2005). Study abroad and second language use: Constructing the self. New York: Cambridge University Press.https://doi.org/10.1017/CBO9780511620584

Ryan, K. (2012). Identity and investment: Issues in an adult education classroom. University of British Columbia, Vancouver.

Sabaruddin, S. (2019). English Language Learning of Indonesian Students during Study Abroad Program in Australia. Indonesian TESOL Journal, 1(1), 27-40. doi:https://doi.org/10.24256/itj.v1i1.543

Savicki, V., \& Cooley, E. (2011). American identity in study abroad students: Contrasts and changes. Journal of College Student Development, 52, 339-349. https://doi.org/10.1353/csd.2011.0035

Vasilopoulos, G. (2015). Language Learner Investment and Identity Negotiation in the Korean EFL Context. Journal of Language, Identity \& Education, 14(2), pp.61-79. https://doi.org/10.1080/15348458.2015.1019783

Wallace, C. (2003). Critical reading in language education. Basingstoke, UK: Palgrave Macmillan. https://doi.org/10.1057/9780230514447

Yin, R. K. (2012). Applications of case study research (5th ed.). Thousand Oaks, CA: Sage. 